\title{
Management and prognosis of pancreatic cancer over a 30-year period
}

\author{
M David', C Lepage', J-L Jouve', V Jooste', M Chauvenet', J Faivre' and A-M Bouvier*,I \\ 'Inserm U866, Registre des cancers digestifs, Dijon, BP 87900 F-2 1079, France; Université de Bourgogne, Dijon, F-2 1079; CHU, F-2 1079 , Dijon cedex, \\ France
}

\begin{abstract}
BACKGROUND: The aim of this study was to report on changes in the diagnostic assessment, patterns of care and survival over time for pancreatic cancers.

METHODS: A total of 2986 cases of pancreatic cancer from the Digestive Cancer Registry of Burgundy (France) over a 30-year period (1976-2005) were considered. Non-conditional logistic regressions were carried out to identify the factors associated with resection for cure and with the use of chemotherapy. A multivariate relative survival analysis was carried out.

RESULTS: Diagnostic procedures have changed. Ultrasonography and computed tomography progressively have become the major diagnostic procedures. There was a slight improvement in stage: the proportion of stage I-II was $2.8 \%$ in the 1976 - I 980 period and $8.8 \%$ in the $2001-2005$ period $(P<0.001)$. There was a similar trend in the proportion of cases resected for cure, the corresponding percentages being 4.5 and II.3\%, respectively $(P<0.00 \mathrm{I})$. The 5 -year relative survival increased from 2.0 to $4.2 \%(P<0.00 \mathrm{I})$. In the multivariate relative survival analysis, the period remained a significant prognostic factor. Stage, sex, age and histology were independent prognostic factors.

CONCLUSION: Over a 30-year period, there were minor changes in the stage at diagnosis, resection for cure and prognosis of pancreatic cancers, although there were improvements in the diagnostic modalities. Pancreatic cancer still represents a major challenge in oncology.

British Journal of Cancer (2009) I 01, 215-218. doi:10.1038/sj.bjc.6605 I50 www.bjcancer.com

Published online 30 June 2009

(c) 2009 Cancer Research UK
\end{abstract}

Keywords: pancreatic cancer; cancer registry; management; stage at diagnosis; survival

Pancreatic cancer is currently generating particular interest because of its increasing incidence and its particularly poor prognosis. Numerous developments have taken place in postoperative resuscitation and non-surgical treatments. These were initiated in specialised centres and have progressively spread. Population-based studies that include all of the cases arising in a well-defined population are the best way to assess the real management of these cancers. The objective of this study was to draw a picture of the trends in pre-therapeutic evaluation, stage at diagnosis, treatment and survival of pancreatic cancers in a welldefined French population over the past 30 years.

\section{MATERIALS AND METHODS}

The population-based digestive cancer registry of Burgundy (France) records all digestive tract cancers diagnosed in the resident population of two administrative areas (1 050000 according to the 1999 census). Cancer extension at the time of diagnosis was classified according to the TNM classification. Three stages were defined: stage I-II (T1-4 N0 M0), stage III (N1 M0) and stage IV (M1). Non-resected cancers with no evidence of

*Correspondence: Dr A-M Bouvier;

E-mail: anne-marie.bouvier@u-bourgogne.fr

Received 9 December 2008; revised 19 May 2009; accepted I June 2009; published online 30 June 2009 visceral metastasis were grouped into stage IV and classified as advanced cases $(n=1301)$. Those who underwent resection, but were not staged, were classified as unknown $(n=9)$. The life status was known for 2968 patients (99.0\%) in January 2008.

Relative survival was calculated. The excess hazard ratio of death was estimated using a relative survival model based on the general linear model. A total of 2986 pancreatic cancers were considered. Ampullary, intrapancreatic bile duct and duodenal cancers were excluded.

\section{RESULTS}

\section{Diagnostic modalities}

Diagnostic procedures varied over time (Table 1, Figure 1). There was a dramatic decrease in the proportion of cases diagnosed at the time of laparotomy. The diagnosis was based on surgical findings in $37.4 \%$ of the cases over the $1976-1980$ period, and in $3.5 \%$ of the cases over the 2001-2005 period. Laparoscopy as a diagnostic tool was used until 1985: $31.3 \%$ of patients between 1976 and 1980, and in $13.9 \%$ of cases between 1981 and 1985. The proportion of patients who had an abdominal ultrasound (US) examination increased from 6.5\% (1976-1980) to 87.3\% (19911995), then tended to decrease. Computed tomography (CT) scans were introduced in 1981 . It was carried out in $2.4 \%$ of the cases over the 1981-1985 period and in 79.5\% over the 2001-2005 
Table I Trends in diagnostic procedures, stage and management of pancreatic cancers (\%)

\begin{tabular}{|c|c|c|c|c|c|c|}
\hline & $\begin{array}{c}1976-1980 \\
(N=246)\end{array}$ & $\begin{array}{c}198|-| 985 \\
(N=330)\end{array}$ & $\begin{array}{c}1986-1990 \\
(N=479)\end{array}$ & $\begin{array}{c}1991-1995 \\
(N=528)\end{array}$ & $\begin{array}{c}1996-2000 \\
(N=665)\end{array}$ & $\begin{array}{c}200 \mathrm{I}-2005 \\
(N=738)\end{array}$ \\
\hline \multicolumn{7}{|l|}{ Procedures used for diagnosis } \\
\hline Surgical findings & 37.4 & 40.6 & 26.7 & 5.5 & 3.5 & 3.5 \\
\hline Cholangiography $^{a}$ & 10.0 & 5.1 & 10.4 & 8.8 & 6.7 & 3.2 \\
\hline Ultrasonography & 6.5 & 26.7 & 39.0 & 87.3 & 83.9 & 65.6 \\
\hline $\begin{array}{l}\text { Computed } \\
\text { tomography }\end{array}$ & 0.0 & 2.4 & 27.1 & 54.6 & 74.6 & 79.7 \\
\hline $\begin{array}{l}\text { Magnetic resonance } \\
\text { imaging }\end{array}$ & - & - & - & 1.1 & 10.5 & 9.1 \\
\hline $\begin{array}{l}\text { Endoscopic } \\
\text { ultrasonography }\end{array}$ & - & - & - & 8.9 & $\mid 1.1$ & 28.5 \\
\hline \multicolumn{7}{|l|}{ Stage at diagnosis ${ }^{\mathrm{b}}$} \\
\hline$|/| \mid$ & 2.8 & 4.6 & 7.8 & 10.4 & 8.0 & 8.8 \\
\hline III & 2.0 & 1.2 & 2.5 & 4.8 & 6.3 & 5.7 \\
\hline Advanced $^{c}$ & 95.2 & 94.2 & 89.7 & 84.8 & 85.7 & 85.5 \\
\hline \multicolumn{7}{|l|}{ Treatment } \\
\hline Resection for cure & 4.5 & 4.5 & 8.7 & 12.5 & 11.0 & 11.3 \\
\hline Palliative surgery & 57.2 & 65.9 & 55.7 & 48.5 & 53.3 & 48.8 \\
\hline $\begin{array}{l}\text { Palliative } \\
\text { chemotherapy }\end{array}$ & 1.7 & 3.5 & 4.4 & 10.4 & 28.5 & 41.8 \\
\hline Palliative radiotherapy & 0.0 & 7.7 & 4.2 & 4.8 & 12.5 & 8.8 \\
\hline Best supportive care & 37.4 & 25.7 & 34.0 & 37.4 & 33.2 & 38.7 \\
\hline
\end{tabular}

${ }^{a}$ Retrograde or trans-hepatic diagnostic cholangiography. ' Unknown: nine cases. ${ }^{c}$ Metastatic and/or non-resected cases. ${ }^{d}$ Including medical biliary stent.

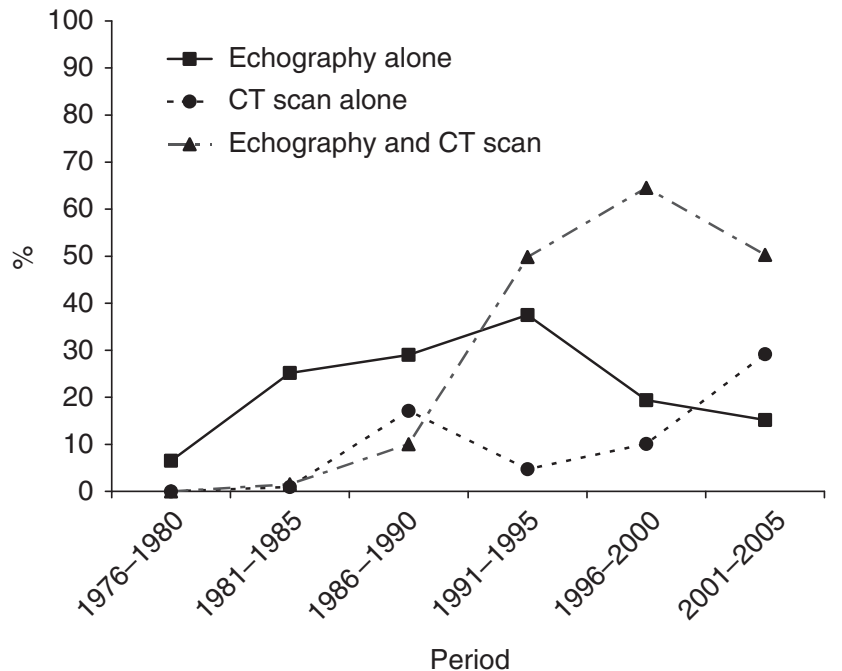

Figure I Evolution of imaging in diagnosis strategy

period $(P<0.001)$. Endoscopic ultrasonography emerged in the early 90 s and was carried out in $28.5 \%$ of cases during the $2001-$ 2005 period. The use of MRI, which was available since 1991, remained infrequent.

\section{Stage at diagnosis and treatment}

The proportion of stages I and II increased over the first four study periods from 2.8 to $10.4 \%(P<0.001)$, then levelled out. Most cases of pancreatic cancers were advanced cases.

The proportion of patients who underwent resection for cure was stable over the first two study periods, increased between the third (1986-1990) and the fourth (1991-1995), and then remained stable $(P<0.001)$ (Table 1$)$. The proportion of these patients receiving adjuvant chemotherapy increased from 5.0\% (1986$1990)$ to $40.2 \%(2001-2005)$. Overall, $22.7 \%$ of the patients aged $<65$ years were resected for cure. This decreased to $13.7 \%$ of those aged from 65 to 74 years and to $7.8 \%$ of patients aged $>75$ years $(P<0.001)$. Operative mortality after surgery for cure decreased significantly over the study period. It was $28.0 \%$ over the $1976-$ 1985 period, $9.5 \%$ over the $1986-1995$ period and $5.1 \%$ over the 1996-2005 period $(P<0.001)$.

Chemotherapy was carried out after resection for cure in $19.4 \%$ of the cases. This proportion was $41.8 \%$ during the last study period. Chemotherapy was carried out in $30.4 \%$ of the cases after palliative resection and in $16.6 \%$ in non-resected cases $(P<0.001)$. Before 1990 , palliative chemotherapy was hardly used $(3.5 \%$ of cases). The proportion of patients receiving palliative chemotherapy increased from $10.4 \%(1991-1995)$ to $41.8 \%$ in the last study period $(P<0.001)$. Radiotherapy was also used as a palliative treatment. It emerged after the first period and remained rarely used ever since.

\section{Survival}

Overall 1- and 5-year relative survival rates were, respectively, 19.8 and $4.1 \%$. Survival was higher in females than in males $(P<0.001)$, in patients under 65 years than in older patients $(P<0.001)$ and in endocrine tumours compared with the other histological types $(P<0.001)$ (Table 2$)$. The 5 -year relative survival increased from 2.0 to $4.2 \%$ between the first and the last time periods $(P<0.001)$. Stage was the most important determinant of survival. The 5-year relative survival rate was $25.7 \%$ after resection for cure and $2.0 \%$ for the other treatment modalities $(P<0.001)$.

In the multivariate relative survival analysis, sex, age, histological type, stage and period of diagnosis were significant prognostic factors.

\section{DISCUSSION}

The data presented here report the management and survival of pancreatic cancers at a population level over 30 years. 
Table 2 Prognostic factors for pancreatic cancers: univariate and multivariate relative survival analysis

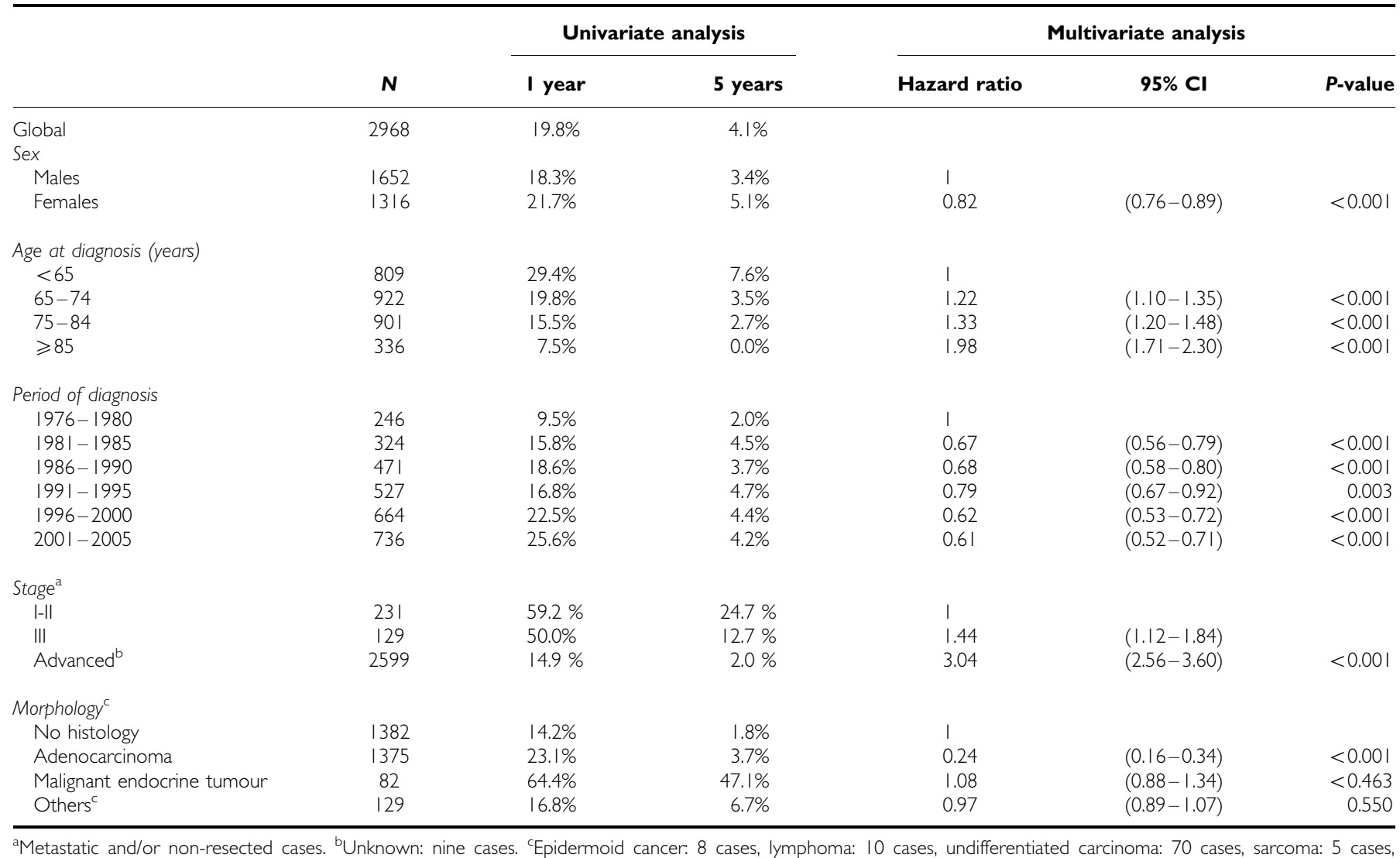

cystadenocarcinoma: 36 cases.

One point of interest of this study was to describe changes in the diagnostic assessment of pancreatic cancer. No comparable data are available in the literature. Until the early 1980s, exploration of the pancreas was difficult, which explains why diagnosis was often based on operative findings. This was the case in nearly $40 \%$ of cancers over the 1976-1985 period in our study. Diagnosis became easier with the development of abdominal US examination and then of CT. Both of these investigations were often carried out, in particular over the 19962000 period. In the most recent period, there was a trend to carry out CT directly. MRI imaging is still rarely used, whereas the importance of endoscopic ultrasonography is increasing. Thus, it is clear that the development of medical imaging has made diagnosis easier.

Changes in diagnostic strategies were not associated with a major improvement in the stage at diagnosis. The lateness of symptoms can explain why only limited improvements in the management of pancreatic cancer can be expected from the development of diagnostic strategies. The proportion of patients resected for cure increased from 4.5 to $11.3 \%$ and the proportion of those in stage I-II increased from 2.8 to $8.8 \%$. The fact that improvements were seen in the first three 5-year periods, before levelling off during the three following periods, is disappointing. Resection rates for cure and stage were lower than those reported in hospital-based series (Bilimoria et al., 2007). Hospital data were provided by specialised units and as such cannot be used as a reference.

New approaches to the treatment of pancreatic cancer need to be found. The benefits of adjuvant treatment using chemotherapy and/or radiotherapy have been reported (Stocken et al., 2005). However, the benefits on survival, although significant, are modest. Palliative chemotherapy regimens also improve survival (Sultana et al., 2008). One of the most striking trends in the management of pancreatic cancer lies in the reduction of operative mortality, in particular after surgery for cure. It was $5 \%$ over the last 10-year period, close to figures reported by specialised teams. Major advances have been made by the way of the thorough evaluation of associated medical conditions and by improvements in post-operative resuscitation.

The prognosis of pancreatic cancer remained markedly grim, with $<5 \%$ of survivors 5 years after diagnosis. The survival rates reported here are comparable with those of the US Surveillance Epidemiology and End Results database (Ries et al.), the EUROCARE database (Sant et al., 2003), and with the England and Wales national registry (Mitry et al., 2008). Stage was the major determinant of survival. Our data also showed a worse prognosis in men than in women. This had already been reported (Eloubeidi et al., 2006). At the same age, women probably have lesser comorbidity than men. The much better prognosis of endocrine tumours has already been reported (Fesinmeyer et al., 2005). The development of these tumours is thought to be slow (Lepage et al., 2004). In this situation, aggressive treatments are justified.

As symptoms of pancreatic cancer appear late, it is necessary to make advances in a better understanding of the genetic and environmental causes, and of the mechanisms involved in its development. Smoking is the most consistently identified risk factor, although its role is not as important as for other cancers. The risk of pancreatic cancer seems to be greater in people having high-energy diets and lower in those having diets that are rich in fruits and vegetables. Detection of asymptomatic pancreatic cancers remains a challenge, as high-risk groups for pancreatic cancer are not sufficiently known. The association between diabetes and pancreatic cancer has long been recognised. However, the prevalence of pancreatic cancer is low. A reliable serological biomarker with a high likelihood of underlying asymptomatic pancreatic cancer is needed to yield a successful screening strategy. In addition, improvements in treatment are still needed. 


\section{REFERENCES}

Bilimoria KY, Bentrem DJ, Ko CY, Stewart AK, Winchester DP, Talamonti MS (2007) National failure to operate on early stage pancreatic cancer. Ann Surg 246: $173-180$

Eloubeidi MA, Desmond RA, Wilcox CM, Wilson RJ, Manchikalapati P, Fouad MM, Eltoum I, Vickers SM (2006) Prognostic factors for survival in pancreatic cancer: a population-based study. Am J Surg 192: $322-329$

Fesinmeyer MD, Austin MA, Li CI, De Roos AJ, Bowen DJ (2005) Differences in survival by histologic type of pancreatic cancer. Cancer Epidemiol Biomarkers Prev 14: 1766-1773

Lepage C, Bouvier AM, Phelip JM, Hatem C, Vernet C, Faivre J (2004) Incidence and management of malignant digestive endocrine tumours in a well defined French population. Gut 53: 549-553

Mitry E, Rachet B, Quinn MJ, Cooper N, Coleman MP (2008) Survival from cancer of the pancreas in England and Wales up to 2001. Br J Cancer 99(Suppl 1): S21-S23

Ries L, Young J, Keel G, Eisner M, Lin Y, Horner M-J. Cancer survival among adults: US SEER program, 1988-2001; Chapter 7: Cancer of the Pancreas. http://seer.cancer.gov/publications/survival/surv_pancreas.pdf : 2008 Sept 22 Sant M, Aareleid T, Berrino F, Bielska Lasota M, Carli PM, Faivre J, Grosclaude P, Hedelin G, Matsuda T, Moller H, Moller T, Verdecchia A, Capocaccia R, Gatta G, Micheli A, Santaquilani M, Roazzi P, Lisi D (2003) EUROCARE-3: survival of cancer patients diagnosed 1990-94 - results and commentary. Ann Oncol 14(Suppl 5): v61-v118

Stocken DD, Buchler MW, Dervenis C, Bassi C, Jeekel H, Klinkenbijl JH, Bakkevold KE, Takada T, Amano H, Neoptolemos JP (2005) Metaanalysis of randomised adjuvant therapy trials for pancreatic cancer. $\mathrm{Br}$ Cancer 92: $1372-1381$

Sultana A, Tudur Smith C, Cunningham D, Starling N, Neoptolemos JP, Ghaneh P (2008) Meta-analyses of chemotherapy for locally advanced and metastatic pancreatic cancer: results of secondary end points analyses. Br J Cancer 99: 6-13 